This is a post-refereeing final draft. When citing, please refer to the published version:

Cohen, E. and Cohen, S.A. (2012). Authentication: Hot and Cool. Annals of Tourism Research, 39(3), 1295-1314. DOI: 10.1016/j.annals.2012.03.004

\title{
Authentication: Hot and Cool
}

Erik Cohen

Dept. of Sociology and Anthropology, The Hebrew University of Jerusalem, Israel

Scott A. Cohen

School of Hospitality and Tourism Management, University of Surrey, United Kingdom

\begin{abstract}
Seeking to shift the discussion of the concept of authenticity in tourism scholarship from the dominant concern with tourist experiences to the more sociological problem of the processes of authentication of tourist attractions, we conceptualize two analytically distinct, but practically often intersecting, modes of authentication of attractions, "cool" and "hot". Through a range of examples, we demonstrate the implications of the two modes for the dynamics of the constitution of tourist attractions, examine their interaction, and illustrate how "cool" and "hot" authentication can be conducive to different types of personal experiences of authenticity. We furthermore explore the crucial question of who is authorized to authenticate tourist attractions, and thereby uncover issues of power and contestation in the politics of authentication.
\end{abstract}

Keywords: authentication, authenticity, performativity, power, tourist attractions 


\section{INTRODUCTION}

The sociological treatment of the relationship between tourism and modernity has been focused on the concept of "authenticity," ever since MacCannell $(1973 ; 1976)$ introduced it into the academic discourse of tourism in the 1970s, in his argument regarding the "staged authenticity" of tourist attractions. In the wide-ranging discussion following MacCannell's opening, the concept has been interpreted and re-interpreted in various ways with regard to such issues as the nature of authenticity, its construction and experience (e.g. Cohen, 1988; 2007a; Crang, 1996; Olsen, 2002; Bruner, 2005; Reisinger \& Steiner, 2006; Steiner \& Reisinger, 2006a; Belhassen, Caton \& Stewart, 2008; Buchmann, Moore, \& Fisher, 2010; Knudsen \& Waade, 2010; Lau, 2010; Rickly-Boyd, 2012). However, the discussion failed to lead to a broad consensus, which would make authenticity the anchor of a general paradigm for the study of modern tourism, but instead resulted in diverse theoretical perspectives (Rickly-Boyd, 2012). The three types of authenticity distinguished by Wang (1999; 2000), objective (object) authenticity (further discussed by Reisinger \& Steiner, 2006; Lau, 2010), constructed authenticity (Cohen, 1988; Olsen, 2002) and existential (subjective) authenticity (Steiner \& Reisinger, 2006a) are still engendering separate discourses, despite some efforts at bridging them (e.g. Rickly-Boyd, 2012).

It is important to note that the three discourses are not on the same level: while objective (object) authenticity and existential (subjective) authenticity denote different types of (personally experienced) authenticity, constructed authenticity does not; rather, it relates implicitly to the process of social construction of the other two types. But, though frequently deployed as a concept, the processes by which authenticity is constructed remain analytically under-developed. Several important questions are still un-explicated: Is there only one or are there several ways by which authenticity is established in the tourism domain? Is there a difference between the processes through which objective, as against existential, authenticity is established? Who has the power to endow tourist attractions with authenticity?

In this article we shall approach these questions from a new perspective: the process of authentication. It should be noted that, whereas the concept of authenticity has been widely discussed in tourism studies, authentication, as the social process by which the authenticity of an attraction is confirmed, remains almost unexplored. The issue of authentication has, however, recently attracted the attention of several researchers (e.g. Alexander, 2009; 
Ateljevic \& Doorne, 2005; Noy, 2009; Xie, 2011). Jackson (1999, p. 101) in fact went so far as to "propose to abandon the search for 'authenticity' and to examine the more tractable question of 'authentication"” instead. Xie (2011), in his discussion of ethnic culture, similarly advocates a shift away from authenticity to an emphasis on processes of authentication. However, such programmatic declarations did not yet lead to a systematic theoretical elaboration of the concept. In this article we start to do so, by distinguishing two contrasting modes of authentication, "cool" and "hot," and discussing their wider implications.

We define "authentication" as a process by which something - a role, product, site, object or event - is confirmed as "original", "genuine", "real" or "trustworthy". We aim to show that, at least in the field of tourism, there exist two different, yet often co-constitutive, modes of that process: however, whereas "cool" authentication corresponds to accepted common-sense and dictionary definitions of the term, "hot" authentication differs from them. The conceptualization and documentation of the latter, with regard to the field of tourism, is thus the principal aim of this article. Second, we aim to show that these processes do not only differ in the manner in which they establish the authenticity of attractions, but also in the manner in which they influence the cultural, social and political dynamics of the authenticated phenomena. Third, we shall seek to demonstrate that the two kinds of authentication are conducive to different kinds of personal experiences of authenticity. Finally, we shall examine the patterns of interaction between the two modes of authentication in several actual situations. Many of our examples are drawn from the previous empirical research of one of the present authors. As much of this research has taken place in non-Western contexts, the examples offer a fresh alternative to the Occidentalocentric focus that has characterized the majority of past studies of authenticity in tourism.

We have built our conceptual approach on Tom Selwyn's (1996, p. 21-28) seminal distinction between "hot" and "cool" authenticity. Though possibly similar aims underpin both our distinctions, we employ the dichotomy in somewhat different ways than Selwyn did, and draw from it different implications. Selwyn (1996, p. 20-21) conceived of "hot" authenticity as that "aspect of the imagined world of tourist make-believe...concerned with questions of self and society," in particular with the quest for an "authentic self" and "authentic other." Selwyn (ibid, p. 24) exemplifies the concept of hot authenticity through Golden's (1996) case study of the Diaspora Museum in Tel-Aviv, which enables (Jewish) visitors to plot "their individual genealogies back through several generations [and thereby] locate themselves... within a wider framework of the diaspora," a proceeding by which "the 
authenticity of the visitors' selves is confirmed in relation to the social life depicted by the museum." In contrast, Selwyn distinguishes the concept of "cool" authenticity as "reserved for propositions which aim to be open to the kinds of procedures described by Popper [i.e. are subject to falsification]... which would like to claim a different kind of legitimacy from those in the former category [i.e. that of hot authenticity]."

Selwyn thus seems to distinguish between a "social" and a "scientific" version of authenticity, or in more theoretical terms, an "emic" and an "etic" one - one espoused by the tourists, the other representing a theoretical top-down approach. We retain the terms "hot" and "cool", however, in constructing our present argument, rather than for instance "emic/etic" or "social/scientific", because these terms are loaded with an emotive power that we seek to harness. While making a parallel conceptual distinction with regard to processes of authentication, our aim goes beyond Selwyn's: we seek to re-direct the discourse of tourism away from the dominant socio-psychological concern with the tourists' experience and focus instead on the distinct social and political processes associated with each mode of the authentication of tourist attractions.

\section{THE TWO MODES OF AUTHENTICATION}

To designate something as authentic is associated with the conferring of status and is bound up with issues of power (Xie, 2011). To this end, Xie identifies key stakeholders, including governments, tourism businesses, tourists and ethnic communities, as implicated in the authentication of ethnic tourism products. Xie's principal goal is to investigate how stakeholders make claims to, and attempt to legitimate, their constructions of ethnicity and culture as against similar attempts by others. Similarly, Ateljevic and Doorne (2005) view authentication through a dialectical lens in which authenticity is mutually negotiated between producers (local tourism entrepreneurs) and consumers (tourists). Yet, neither Xie (2011) nor Ateljevic and Doorne (2005), nor any other author, have sought to distinguish or conceptualize different kinds of social processes through which the authenticity of various tourism attractions is confirmed or authenticated.

We have distinguished two such processes, "cool and "hot" authentication. However, rather than attempt just to contrast the dichotomous terms to one another, we shall show how the two processes of authentication are interlinked, as the dynamics of one intersects with that 
of the other, contributing to a fluid, and sometimes politically rife and unstable, relationship. We shall thereby raise issues of power that are bound up and hidden in inscriptions of authentication.

It is important to note, that in examining authentication in the context of tourist attractions, we do not seek to perpetuate a worldview of tourism as separate from everyday life. Rather, as tourism is increasingly imbricated with other realms of life (Edensor, 2007; Gale, 2009), from the mundane through the sacred, our discussion necessarily engages domains of art, folklore, religion, archaeology and science as they interrelate with tourism.

Authentication endows an object, site or event with authenticity; it thus involves performativity, a concept introduced into linguistic philosophy by John Austin (1970), which has been recently induced into the discourse of authenticity by Knudsen and Waade (2010). However, as we illustrate below, "performativity" can be deployed in two different senses: in "cool" authentication it is typically an explicit "performative speech act" (Austin, 1970, p. 242), whereas in "hot" authentication it becomes, as implied in the use of the term by Knudsen and Waade (2010), a constitutive performative process.

\section{"Cool" Authentication}

"Cool" authentication is typically a single, explicit, often formal or even official, performative (speech) act, by which the authenticity of an object, site, event, custom, role or person is declared to be original, genuine or real, rather than a copy, fake or spurious. Acts of "cool" authentication may be based on scientific knowledge (cf. Selwyn 1996, p. 26), on expertise, on personal knowledge claims or on divine inspiration. But it is important to note that coolly authenticating acts will be effective only if deployed by an identifiable authenticating agent, whether historical or contemporary, who is deemed entitled by her or his personal charisma, institutional position, privileged knowledge or social or religious status to perform such acts. Nonetheless, such acts do not necessarily lead to consensus. Rather, they are often open to criticism, resistance, controversy or negotiation (Ateljevic \& Dorne, 2005).

In contemporary society, "cool" authentication is frequently formally granted by "certification;" in a similar, but broader sense, the process by which a role or institution is evaluated and recognized as "meeting certain predetermined standards or qualifications" is known as "accreditation" (Morrison, Hsieh \& Wang, 1992, p. 33). These procedures are 
common in fields in which genuineness or truthfulness play a crucial role, such as in the art and antiques trade, or in the professions, such as medicine or engineering, in which the veracity of a diploma or permit plays a critical role in gaining a client's trust. However, it is important to point out the relativistic implications of our definition: the validity of any "cool" authentication depends on the kinds of procedures by which it is established (or claimed to be established). There are therefore far-reaching manipulative opportunities implicit in acts of "cool" authentication, as we shall yet see.

In the domain of tourism, however, in comparison with such domains as art or medicine, "the level of authentication is very low," as MacCannell (1976, p. 14) already observed long ago in his discussion of "staged authenticity". There exist few, if any, formal criteria or accepted procedures to determine and codify the authenticity of attractions. Tourist attractions or tourist-oriented products are also rarely formally certified. There exist some environmental accreditation schemes, such as Green Globe, that provide certification of the sustainability of the operations and management of tourism companies and their suppliers (Font, 2002). However, such schemes seek to audit and accredit products for recognition and acceptance in the marketplace through a set of established standards, rather than certify a product as genuine or original.

Some certifications are based on expert institutional authentication, as for example those that seek to convey a "content of authenticity" or genuineness to the physical attributes of a geographic area and/or the culture of its inhabitants; prominent among these on a global scale are the "World Heritage Sites" (WHS), certified by the United Nations Educational, Scientific and Cultural Organization (UNESCO) (Lorenzini, Calzati \& Giudici, 2011, p. 542). Indigenous people have also made efforts to gain institutional power to legally authenticate tourist-oriented objects, by certification of souvenirs and crafts as "handmade", or made by indigenous producers, as, for example, the certification system sought by the Aotearoa Maori Tourism Federation for control over standards of authenticity of Maori tourism products in New Zealand (Ryan, 1997). The flip-side of such efforts is to seek to prevent unauthorized reproduction of aboriginal peoples' art products. Thus, Canada's 1988 Copyright Act, "prohibits unauthorized reproductions of an [aboriginal] artist's work" (Blundell, 1993, p. 71), while its Consumer and Corporate Affairs agency seeks to prevent the deceptive marketing of imitation aboriginal artwork, known as "fakelore" (ibid, p. 74) (in practice, however, as Evans-Pritchard [1987, p. 291] observes in the context of Native American crafts, "no art has a pristine unilineal tradition" and the distinctions between "folklore" and 
"fakelore" can become blurred or create tensions amongst stakeholders). In most non-Western countries, however, few efforts have been made to formally protect, authenticate or certify the craft and art products of tribal and other minority peoples.

Aside from such examples, the "cool" authentication of tourist attractions is largely vague and devoid of a firm institutional or legal basis. It is generally unclear who has the authority to authenticate tourist attractions; the field is thus open to manipulation and contestation. Thus Koontz (2010) demonstrates how producers and marketers seek to enhance the appeal of their products (including some in the domain of tourism), and distinguish them from mainstream everyday mass-products, by authenticating them as either reflecting the Other ("othering") or some pre-modern "tradition" ("traditionalizing" in Kooontz's terms). Such vague and unregulated forms of authentication facilitate the virtually unrestricted staging of the authenticity of tourist attractions.

"Coolly" authenticated objects, sites or events typically evoke appreciation with an emotional overtone - as when a visitor to a museum appreciates a "real" painting by Brueghel or Franz Hals (as against reproductions or fakes), or a tourist favors an authenticated "genuine" piece of folk art or performance of a local custom, over a contrived one. We hence suggest that in the domain of tourism, "cool" authentication tends to be conducive to personal experiences of "objective (object) authenticity" (Belhassen, Caton \& Stewart, 2008; Lau, 2010).

\section{"Hot" Authentication}

"Hot" authentication is an immanent, reiterative, informal performative process of creating, preserving and reinforcing an object's, site's or event's authenticity. It is typically an anonymous course of action, lacking a well-recognized authenticating agent. The process of "hot" authentication is emotionally loaded, based on belief, rather than proof, and is therefore largely immune to external criticism. "Hot" authentication involves a high degree of commitment and self-investment on part of the participants. It is an accumulative, selfreinforcing process: the performative practices by and between visitors help to generate, safeguard and amplify the authenticity of the visited site or event. The persistence of "hot" authentication depends on reiterative performative reinforcement by such practices as paying obeisance, worshipping, venerating, witnessing, making offerings or taking vows; these 
practices are often accompanied by emotional expressions of commitment, devotion or identification with the venerated object, site or event. The relationships between social actors, when performing acts of "hot" authentication, are often characterized by a sense of communitas (Turner, 1973).

The veneration of, or devotion to, "hotly" authenticated objects or sites is frequently expressed materially in items, such as in offerings of votive objects, candles, flowers, and various other prestations, as well as in graffiti, inscriptions and written supplications presented or left by visitors. The accumulation of such items around the venerated object or site in turn reinforces and augments its "hot" authentication for visitors.

The principal differences between the two processes of authentication can be summed up as follows: "Cool" authentication is declarative, often based on a "proof"; "hot" authentication is implicit, based on belief. "Cool" authentication is enacted without the participation of the public - its effectiveness depends on the credibility of the authenticating authority; "hot" authentication is not explicitly enacted, but socially produced in a participatory process. "Cool" authentication tends to be static, independent of the visiting public; "hot" authentication is dynamic, maintained and augmented by the visitors' performative practices. "Cool" authentication is typically constituted by a single act; "hot" authentication is built up gradually, in an ongoing process. "Hot" authentication is thus an affective self-reinforcing process in which the sacredness, sublimity, or genuineness of sites, objects or events is constantly perpetuated, confirmed (and augmented) by public practice, rather than by some declaration. This perpetuation is often externally expressed by material symbols of veneration, left behind by visitors.

The distinguishing traits of "hot" authentication are well illustrated by a case study, carried out by one of the authors, on the ascent of the "Naga fireballs" from the Mekong river, on the border between Laos and northeastern Thailand, during the ok pansa festival (the end of pansa, the Buddhist rainy season retreat, popularly known as the "Buddhist Lent"). The mythological Naga serpents (phayanak) are believed to live in the depths of the river, and to shoot the fireballs from there in celebration of Buddha's return from heaven, where he had taught his mother Dharma during the pansa period. Thousands of people assemble at the banks of the river, shouting in excitement whenever a fireball is observed. Several alternative explanations of the phenomenon have been offered: some claimed that it is a natural phenomenon, others that it is man-made, but neither explanation had much impact on the 
widespread belief that it is a supernatural event (Cohen, 2007b). This belief continues to support the flow of worshipers to the banks of the river; and their excitement, in turn, supports the belief in the supernatural source of the event. The worshipers are thus not just "spectators;" they form a community of believers, implicated in the event itself, contributing to, and strengthening, its "hot' authentication.

This example is telling, precisely because there are competing alternative explanations of the event, which, if accepted, would deny its supernatural origins, debunk it as a fake, or at least "coolly" authenticate it as a rare natural phenomenon (ibid). But unlike visitors to the Great Geyser in Iceland or the Old Faithful in Yellowstone National Park, Wyoming, the continuous attractiveness of the Naga fireballs is not sustained by excitement over the powers of nature, but rather over their mysterious, supernatural origins.

Our conceptualization of "hot" authentication resembles Geertz's (1973, p. 90) definition of religion as a self-reinforcing system, in which "powerful, pervasive and longlasting moods and motivations" are formulated into "conceptions of a general order of existence" and clothed "with such an aura of factuality" that those "moods and motivations seem uniquely realistic". However, Geertz's definition is formulated on the symbolic and thus ultimately intellectual level, while ours is formulated on the level of praxis: the belief strengthens the (ritual) performance, and the performance strengthens the belief. As Smith (1987, p. 28) observes regarding the conferring of meaning to "place" through practice "human beings are not placed, they bring place into being". "Hot" authentication therefore imbricates the individual in a way in which "cool" authentication does not: he or she is part of the authentication process, rather than only an observer of a site, object or event, authenticated by others.

We suggest that performative practices of "hot" authentication, whether at a site, event or towards an object, engage the individual and are often conducive to personal experiences of "existential authenticity", a state of being, associated with "having a sense of one's own identity" (Steiner \& Reisinger, 2006a, p. 300; see also Kim \& Jamal, 2007; Wang, 1999). Such experiences are generally spontaneous and serendipitous, akin to Cary's (2004, p. 64) "tourist moment", in which perceptions of "self-discovery and communal belonging" give rise to a temporary feeling of existential "truth". Oakes (2006, p. 237) similarly shows how authenticity is reified through intersubjective encounters as "that ideal moment when alienation disappears and the fragmented world becomes whole again". Existential 
authenticity can consequently be viewed as an experiential reflection of the individual's performative participation in the process of "hot" authentication.

Self-invested in performative practices of authentication, the adherents or promoters of the "hot" authentication of an object, site or event are generally resistant to criticism or "cool" proofs of deceit or falsification, and often hostile to attempts to discredit or deauthenticate it. A rather extreme example of the latter is the controversy over a legendary heroine, Thao Suranari (Lady Mo, see Korat Post, 2007) whose statue in Nakhon Ratchasima (or Korat), the principal city of northeastern Thailand, has become "a religious landmark for the people of Korat and... of the northeastern region generally" (Jory, 2003), and a major source of income for providers of devotional offerings to the heroine. In 1995 a master's thesis on Thao Suranari was published as a book. It revealed that,

"[T]here is no evidence...to indicate the existence, let alone heroism, of Thao Suranari...This thesis was interpreted as a slight on the people of Korat. Demonstrations... by various groups, goaded on by local politicians [demanded] that the book be burned, that [the author] apologize to the monument, and that her master's degree be withdrawn. Eventually [the publisher] was forced to recall the book; [the author] went into hiding and was later transferred from her school in Nakhon Ratchasima to another province" (Jory, 2003; see also Keyes, 2002).

An attempt at "cool" de-authentication of the venerated site was thus thwarted by the supporters of its "hot" authentication, and by powerful local leaders, who had a vested interest in preserving and augmenting the cult of Thao Suranari. One of the present authors, who has followed the development of the site for many years, found on his recent visit in 2011 that the scope of veneration of the heroine has expanded considerably since the dispute, with a large number of stalls surrounding the monument making a living by providing flowers, candles and other ritual articles to the worshippers. The rich display of these ritual paraphernalia strengthens the "hot" authentication of the heroine, and serves as an impediment to any further attempt to "coolly" de-authenticate it.

The differences between "cool" and "hot" authentication, discussed above, are schematically presented in Table 1. 


\begin{tabular}{|c|c|c|}
\hline Criterion & Cool authentication & Hot authentication \\
\hline Basis of authority & $\begin{array}{l}\text { Scientific knowledge claims, } \\
\text { expertise, proof }\end{array}$ & Belief, commitment, devotion \\
\hline Agent & Authorized person or institutions & $\begin{array}{l}\text { No single identifiable agent, } \\
\text { performative conduct of } \\
\text { attending public }\end{array}$ \\
\hline Approach & $\begin{array}{l}\text { Formal criteria, accepted } \\
\text { procedures }\end{array}$ & Diffuse and incremental \\
\hline Role of public & Low, observer & High, imbricated, participatory \\
\hline Practices & $\begin{array}{l}\text { Declaration, certification, } \\
\text { accreditation }\end{array}$ & $\begin{array}{l}\text { Ritual, offerings, communal } \\
\text { support, resistance }\end{array}$ \\
\hline Temporality & Single act, static & Gradual, dynamic, accumulative \\
\hline $\begin{array}{l}\text { Conducive to personal } \\
\text { experiences of }\end{array}$ & Objective authenticity & Existential authenticity \\
\hline Continuance & Dependent on credibility of agent & $\begin{array}{l}\text { Reiterative, requires continual } \\
\text { (re)enactment }\end{array}$ \\
\hline $\begin{array}{l}\text { Impact on dynamics of } \\
\text { attraction }\end{array}$ & Stagnating effect, fossilization & $\begin{array}{l}\text { Augmentative and } \\
\text { transformative }\end{array}$ \\
\hline
\end{tabular}

We now turn the discussion to how "cool" and "hot" authentication can have a differential impact on the dynamics of the constitution of attractions.

\section{Comparative Dynamics}

We suggest that the two modes of authentication generate two highly distinct dynamics, which often intersect, co-influence or exist in tension with each other. The authoritative, declarative "cool" authentication of an object, site or event is conducive to its isolation from the "flow of everyday life," and might eventuate in its stagnation or fossilization. This 
stagnating effect of "cool" authentication is clearly apparent in the process of "museumization," and is most obvious in the "old-fashioned" museum, in which "coolly" authenticated objects are collected, isolated, de-contextualized and displayed for inspection and appreciation by the visiting public. But stagnation is also common in the so-called "living museums," where local inhabitants are induced or forced to dress and behave in petrified "traditional" ways. Similar stagnating effects can be found in a wide range of other efforts at preservation or conservation of "coolly" authenticated objects, sites or events, such as in official efforts at the protection of local heritage, which prohibit any (external) alterations in old buildings or preserved urban neighborhoods. Fossilization effects are perhaps most extreme in those national parks and heritage sites, from which the inhabitants have been banned in the name of protection of their distinguishing characteristics. Such sites tend to become "'frozen in time' as exotic spectacle[s] for tourist consumption, rather than being allowed to evolve and modernize as an integral and living part of the city [or of any other context]" (Suntikul, Butler \& Airey, 2010, p. 210).

In contrast, "hot" authentication reinforces and augments an object's, site's or event's vitality, and might therefore contribute to its buoyancy, and boost its wider touristic attractiveness. Recent research on performativity in tourism studies (e.g. Knudsen \& Waade, 2010; Noy, 2009), for example, has documented the constitutive role of the public in the (hot) authentication of objects, sites or events of touristic interest. These authors stress that performativity leads to the permeability of barriers between the "stage" and the "audience" at tourist attractions; it perceives the audience or public as implicated in the proceedings, and thereby opens a perspective from which the audience can be seen as constituting or transforming them. Edensor (2001, p. 71) similarly notes that "[b]esides the increasingly staged nature of tourism, tourist space is also (re)produced by tourists, who perform diverse meanings about symbolic places." Baerenholdt, Haldrup, Larsen and Urry (2004) likewise argue that tourists' performances co-produce places.

Since "hot" authentication is produced by the performative conduct of the attending public, the authenticity of a "hotly" authenticated object, site or event emerges incrementally, from often inconspicuous beginnings, and is constantly reinforced with the growth of its popularity, reputation or fame. As "performative norms need to be continually enacted to retain their power" (Edensor, 2001, p. 62), "hot" authentication is an ongoing reiterative process. Thus, the allegedly miraculous apparitions of Virgin Mary (Hermkens, Jansen \& Notermans, 2009) tend to attract devotees, whose "performative action" (Coleman \& Eade, 
2004, p. 15-16) hotly authenticates the site, and thereby attracts additional worshippers. A notable recent example of this process is the case of the Marian apparition in the Catholic Croatian village of Medjugorje (presently in Bosnia and Herzegovina) in 1981 (Bax, 1991; Skrbiš, 2005), which from modest beginnings rapidly gained wide popularity and turned the anonymous village into a major pilgrimage site, attracting millions of devotees. Similarly, the Mekong fireballs have in the past attracted little attention (Cohen, 2007b), but in recent times started to draw huge crowds from all over Thailand, whose size in some years swells to well over 100,000 . The very presence of such big crowds on those sites, and their excitement or devotion, serves to augment the belief in the miraculous nature of the celebrated events, thereby maintaining and re-enforcing their "hot" authentication.

\section{Interactions}

The two modes of authentication in some instances combine without tension and can be seen as co-constitutive of the authenticity of a site. An interesting manifestation of such coalescence is the inclination of visitors to "hotly" authenticate some aspects of otherwise "coolly" authenticated attractions, such as monuments or museum objects. In Thailand, for example, officially erected monuments of Thai kings of the past, executed in a "heroic-realist" style as part of the Thai "civic" religion (Reynolds, 1977), frequently become objects of popular veneration, which "hotly" authenticates these images as possessing some intrinsic power to fulfill the worshippers' supplications. Altars are commonly erected at these monuments, where visitors present offerings of flower garlands and various figurines, and other objects, allegedly appreciated by the deceased kings. Similarly, some important Buddha images, displayed in the National Museum as examples of historical artistic styles, are worshipped in situ by Thai visitors.

Another telling example comes from Noy's (2009) study of the Ammunition Hill Museum in Jerusalem. The "cool" authentication of the museum is provided by the authorities, who choose to locate it on the actual site of the battle for the hill, and display in it original documents and other artifacts (ibid). But that authentication is supplemented by the "hot" authentication of the site by way of the visitors' emotion-loaded inscriptions in the visitor book. Noy (ibid, p. 121) argues that the "[visitor] book offers a compelling stage on which authenticity can be actively performed by the visitors". This performative action by the visitors actually contributes to the expansion of the Museum's exhibition, since, “... whatever 
is registered in/on [the book] instantly becomes part of the exhibit...and thus becomes a (temporary) permanent element in the museum's interior"' (ibid, p. 122).

Implicit in the destabilization of the boundary between stage and audience, is the possibility that the public might not only supplement or reinforce a "cool" authentication of a tourist attraction by enacting a "hot" one, but also display resistance (Edensor, 2001) by subverting officially "coolly" authenticated objects, sites or events. Lacy and Douglass (2002, p. 7) suggest that tourist sites are spaces "within which multiple interpretations of a single ostensible culture can be negotiated, contested and consumed (whether by natives or outsiders)" in "furtherance of cultural, political and economic goals" (ibid, p. 5). Hence the authentication of objects, sites or events, even of those "coolly" authenticated through declarative acts, is not necessarily fixed, but subject to being contested and transformed on the ground. Accordingly, Judith Butler (1990, p. 282, 277) notes that whilst the public (audience) must always act "within the terms of the performance" taking place "on the stage", public (or individual) performances can also "expand the cultural field bodily through subversive performances of various kinds". Individual performances therefore not only mirror and sustain normative boundaries, but have the capacity to transgress and subvert them (Bell, 2008).

The conduct of some tourists at the Blarney Stone in Cork, Ireland is a mild case of such subversion. According to legend, kissing the stone will lead to sudden Irish eloquence; this ritual, which requires a visitor to hang upside down from the parapet of Blarney Castle with the assistance of another person, while sticking one's head through a hole in the castle wall, has been performed by visitors to Blarney Castle for over 200 years and is described as "an exploit brought to life through creative action" (Costa, 2009, p. 91). Over time the attending public has thus "hotly" authenticated the site through its reiterative performance of kissing the stone, despite competing stories over the stone's origins. The site eventually became commodified as a tourist attraction by Blarney Castle Estate, who installed protective iron guiderails and crossbars to prevent risk to participants, alongside charging visitor entrance fees, constructing a souvenir shop and offering coach parking. However, visitors now frequently contaminate the site by sticking their unwanted chewing gum to the wall into which the stone is built. As a result, in 2009 the site was named by TripAdvisor as the world's most unhygienic attraction (The Telegraph, 2009). Such conduct, a travesty of the custom of leaving votive objects at a pilgrimage site, can be seen as a mimicry of it, since the chewing 
gum similarly accumulates through reiterative practice, but also as an implicit expression of disrespect, indicating a deprecation of the belief in the legendary magical power of the stone.

The subversive potential of the public is more forcefully exemplified in Obrador and Carter's (2010) study of Tactical Tourism, a project by a group of artists in Barcelona who are organizing public guided tour interventions, aimed at rescuing subaltern historical voices that have been silenced through dominant narratives. The resistance of the participants to officially endorsed attractions in such tours, perceived by the originators of Tactical Tourism as instances of performative art, ultimately eventuates in the production of newly "hotly" authenticated (alternative) attractions. This project provides substantive evidence of the potential of "hotly" authenticated alternative tourism attractions to subvert "coolly" authenticated sites and events. Such performative acts offer a window into the complex politics in which the dynamics of authentication are often implicated.

\section{The Politics of Authentication}

"Authentication" is not a neutral procedure, but subject to controversy and contestation. Like any other process that creates symbolic goods, it is subject to conflicts of interest and hence implicated in the political process. Bruner (2005, p. 150) argued that a "fundamental question...is not whether an object or site is authentic, but rather who has the authority to authenticate...[t]his is a matter of power". We suggest that the nature of that power is different in each of the two modes of authentication. It tends to be more specific in "cool," and more diffuse in "hot" authentication. Hence the dynamics of the politics of authentication will typically differ in each mode. In the case of "cool" authentication, the power to authenticate is generally vested in some individuals, recognized as "experts", or in certain highly formalized and institutionalized positions, which thereby gain a high degree of unassailable "hegemony" over their field of competence, such as in the authentication of the genuineness of documents, of the competence of persons or establishments to perform certain professional procedures, of the originality of works of art or of archaeological artifacts or of the genuineness of ethnic customs or events.. The "political" question regarding "cool" authentication is how this power is obtained and how it is exercised or contested.

It seems to be generally taken for granted in tourism studies that the power to ("coolly") authenticate tourist attractions is exercised "from above" by some national or 
international agency. An important example of such power is that of UNESCO, which has achieved a hegemonic position in the domain of "cool" authentication and demarcation of natural or cultural sites as "World Heritage Sites (WHS)" on a global scale. The supposed advantages of a WHS site gave rise to a world-wide politics of WHS nominations. This enabled the leading UNESCO officials to exercise their authenticating power in the selection, preservation and conservation of the potential sites from a basically Occidentalist perspective, often overriding national or local preferences or interests (Hitchcock, King \& Parnwell, 2010). Other global institutions might also assert powers of "cool" authentication, but, as the following examples will show, such power is in some instances not fully institutionalized.

International medical travelers are highly dependent on the accreditation of foreigneroriented hospitals in non-Western countries for making their choice of a reliable place for treatment. Accreditation authenticates the competence of these hospitals and of their medical staff (Cook, 2010). There are some well-established accrediting agencies, such as the Joint Commission International, whose accreditations enjoy considerable credibility. With the growing demand of hospitals seeking to be accredited, however, some leading non-Western medical travel hubs created their own accrediting organizations. The reliability of the accreditations of some of the smaller ones has been deemed suspect by Western experts. However, there exists no global authority that regulates or authorizes accreditators (Cohen, 2010, p. 231), opening the field to the creation of ever more accrediting institutions, and to a consequent contestation of their authority. Similar issues exist within environmental schemes, wherein a lack of agreed standards at an international level has prevented any single accreditating body from achieving a widely recognized status on a global scale (Font, 2002).

Since in the domain of tourism there exist few independent authenticating institutions on the global level, the power to authenticate tourist attractions tends to be consolidated in the hands of national governments, which often exercise it "from above", with little consideration for local opinions and attitudes. Thus, for example, Zhongdian County in China was "coolly" authenticated as the "real Shangri-La" by the Yunnan Economy and Technology Research Center, and consequently renamed as Shangri-La County in 2002 by the Chinese government, resulting in a large boost in tourism receipts (Kolås, 2004). This can be seen as an exploitation by the authorities of the preceding "hot" authentication of the locality by mainly Western tourists, based on James Hilton's 1933 novel Lost Horizon, a work that described a fictional utopia, called Shangri-La, in the Tibetan mountains. The "cool" authentication of Zhongdian as Shangri-La, however, was detrimental to other Chinese tourist destinations, such as the 
Yading Nature Reserve and Lijiang town, which had been competing to attract tourists through their own unauthenticated claims to be the "true" site of Shangri-La (Llamas \& Belk, 2011).

The official, "cool" authentication of Zhongdian illustrates how "tradition" is negotiable and subject to often politically motivated invention. As Bendix (1989, p. 132) notes in discussing the "invention of tradition", "[t]raditions are always defined in the present, and the actors doing the defining are not concerned about whether scholars will perceive a given festival or piece of art [or even place] as genuine or spurious but whether the manifestation will accomplish for them what they intend it to accomplish." Disputes and conflicts may therefore arise, as they do in China and elsewhere, regarding the question of who has the power to authenticate.

Owing partly to the weakness of formal procedures in the domain of tourism, the politics of "cool" authentication, are often rife with controversy. Xie (2011) observes that the power to authenticate ethnic cultures in China is bound up with tensions amongst stakeholders, including the government, the ethnic communities, tourism businesses and the tourists themselves. This seems to indicate a growing resistance to the Chinese authorities' tendency to monopolize that power.

"Cooly" authenticating procedures deployed by experts and institutions are sometimes contested by other experts, leading to controversies regarding the authenticity of given objects, sites or events; such controversies are especially common with regard to pieces of art or archaeological finds. Though at surface level they seem to be of a technical or purely scientific nature, such controversies are often based on political motives or considerations. A good example of such politically inspired controversies is the one involving the so-called Ramkhamhaeng Stele in Thailand. In the 1830s the future King Rama IV (Mongkut) claimed to have discovered a stone inscription, purportedly written by King Ramkhamhaeng of the old Siamese kingdom of Sukhothai. The inscription "has been regarded by scholars to date from the $13^{\text {th }}$ century and to be the oldest record of the Thai language and culture...thus becoming the principal icon of national identity" (Glover, 2006, p. 28). That authentication remained undisputed up to the 1980s, when a raucous dispute broke out among Thai scholars on its authenticity (Chamberlain, 1991). Glover (2006, p. 28) notes that a leading Thai archaeologist, 
"[W]as the first to question its antiquity and argued on epigraphic, linguistic and contextual grounds that the inscription could not be earlier than the $15^{\text {th }}$ century. It has also been suggested that the inscription has been made on the order of King Rama IV in order to demonstrate the antiquity and the 'modern' nature of the Thai kingdom at a time when it was coming under pressure from Western colonial powers”.

Though this dispute was framed in scientific terms, it had political overtones: "Bureaucratic scholars - especially those in the Fine Arts Department [associated with the monarchist establishment] - stick to the theory put forward by Rama IV" (Hongthong, 2003), against academics less committed to the establishment's version of Thai history.

Despite the continuous dispute, the stele with the inscription was in 2003 added to UNESCO's World Heritage list (Hongthong, 2003), an achievement reflecting the influence of the conservative scholars on global cultural institutions. Those scholars "after the announcement by UNESCO demanded archaeologists, historians and other scholars to stop being skeptical" (ibid), thus using the UNESCO listing as the ultimate authentication of the inscription. But academic scholars continue to question its purported origins, putting forward various alternative theories (ibid). These are not necessarily intended to de-authenticate the inscription, but to re-posit it into another historical context. "Cool" authentication is thus not a once-for-ever, definitive act; it is subject to revision, which might affect an authenticated object, site or event's status as a tourist attraction.

The politics of "hot" authentication differ significantly in their dynamics from those of its "cool" counterpart. Since "hot" authentication is diffuse and reiterative, there are often no identifiable individuals or institutions whose authenticating authority could be contested or denied. The diffuse nature of "hot" authentication does not, however, imply that performative acts of authentication take place outside of a power structure. Quite to the contrary, seemingly spontaneous performances of "hot" authentication, may be encouraged or opposed for political reasons, especially in order to contest or resist competing political claims or interests.

Consequently, "hotly" authenticated sites could be subject to exploitation, debunked or subjected to restrictive measures by outside forces, to serve different interests. The Medjugorje Marian apparitions are a good case in point. As the popularity of the Medjugorje site grew prior to the collapse of Yugoslavia, the Communist authorities have at first sought to repress it (Bax, 1991, p. 30). While the Franciscan fathers lent the belief in the apparitions their support, the Catholic hierarchy opposed it; the local bishop nominated a commission to 
investigate their "authenticity," but the commission failed to submit any conclusions (ibid, p. 38). After Yugoslavia's collapse, the discourse about the site changed from religious to nationalist, at it came to be exploited as an icon of Croatian nationalism (Skrbiš, 2005). The Holy See, which had never officially recognized the apparitions, became eventually involved in the issue of their veracity: in 2010 it ordered the Congregation of the Doctrine of the Faith to put up an investigating commission (Catholic News Agency, 2010), thus creating the prospect of complementing the site's popular "hot" authentication, with an authoritative "cool" one. This raises an interesting question: how will the present "hot" authentication of the apparitions be affected if the Congregation ultimately refuses to "coolly" authenticate them?

\section{CONCLUSION}

In this article we sought to re-orient the current discussion of authenticity in the tourism literature from the examination of the nature of tourist experiences to the more sociological problem of the sources of authentication of tourist attractions. Its principal innovative argument can be summarized in four interconnected points. First, we conceptualized two analytically distinct, but practically often intersecting, modes of authentication of tourist attractions, "cool" and "hot." While authoritative, declarative "cool" authentication is implicit in discussions of authentication in the literature, "hot" authentication is a new idea. We therefore dwelt at length on its basic properties and explicated the performative social processes through which the "hot" authentication of an attraction is established, maintained and augmented. The principal mechanisms by which these processes operate involve an imbrication of visitors in the attraction, the reiteration of emotive expressions through ritual practices of devotion and veneration, and their external manifestation in material symbols, such as offerings and inscriptions, which in turn serve to augment the "hot" authentication of the attraction.

Second, we suggested that each of these modes is conducive to one of the two principal types of authentic personal experiences discussed in the literature: the "cool" mode to the experience of objective authenticity, the "hot" to the experience of existential authenticity. 
Third, we argued that these modes of authentication constitute the respective dynamics of tourism attractions in contrasting ways: "cool" authentication tends to lead to the stagnation or "museumization" of attractions; in contrast "hot" authentication, requiring continual (re)enactment, will typically lead to a dynamic process of perpetual transformation, or augmentation, of the attraction.

Finally, we turned to the crucial question of who is authorized to authenticate tourist attractions, and uncovered issues of power and authority in the politics of authentication processes. By detailing the comparative dynamics and interactions of the two modes of authentication in a number of actual situations involving the establishment of tourist attractions, we illustrated how authentication is contested and subject to controversy between conflicting interests. Such issues flare up particularly in instances in which processes of "cool" and "hot" authentication clash.

A conceptual article proposing a new perspective on the study of authenticity does have limitations: it cannot effectively deal with all the intricacies of authentication of every kind of tourist attraction. We have in particular abstained from discussing the possible (hot) authentication of overtly staged, contrived attractions, such as Disney World (Moore, 1980), and some other long-established popular theme parks, which arguably have become part of American heritage. We also did not address the complex problem of popular post-modern, make-believe, ludic attractions, such as Santa Claus' circumpolar abodes (Pretes, 1995) or the Burning Man festival in the Black Rock Desert in Nevada (Kozinets, 2002; Sherry \& Kozinets, 2007), which are explicitly contrived, and hence neither "coolly" nor "hotly" authenticated, but may nonetheless elicit subjective experiences of authenticity. An analysis of such attractions would demand a consideration of the wider problem of the status of authenticity (and hence authentication) in post-modern understandings of tourism, which lies beyond the immediate aims of this article.

In conclusion, our analysis has at least two wider implications for tourism studies. The first is for tourism-related place representation. Sharply contrasting "cool" authentication claims may lead to contests between different representations of a locality; "hot" authentication, as a spontaneous process, often engenders blurred and diffuse representations, which may co-exist with one another; but its vagueness often enables the authorities, or other "coolly" authenticating agents, to prioritize one representation of the locality over others, as the example of Medjugorje demonstrates. In this sense, the modes of authentication are 
inextricably linked to how places are identified and how these identifications may be contested.

The second implication concerns the future discourse of authenticity in tourism scholarship. Although our present exposition, owing to a dearth of empirical research, was necessarily speculative and drew where possible on secondary data, we hope that the conceptual basis we have developed will open new avenues of empirical research. Whilst further studies should not discard the leverage that socio-psychological uses of the concept of authenticity have given us in understanding tourist experiences, there remains a clear need for future research that focuses on the nuanced social, political and cultural processes through which tourist attractions are authenticated.

Acknowledgements - We would like to thank Adam Doering (University of Otago), Sean Beer (Bournemouth University), Philip Pearce (James Cook University) and Tom Selwyn (School of Oriental and African Studies) for their insights and comments on earlier drafts of this article.

\section{REFERENCES}

Alexander, N. (2009). Brand authentication: Creating and maintaining brand auras. European Journal of Marketing, 43(3/4), 551-562.

Ateljevic, I. \& Doorne, S. (2005). Dialectics of authentication: Performing 'exotic otherness' in a backpacker enclave of Dali, China. Journal of Tourism and Cultural Change, 3(1), 117.

Austin, J.L. (1970). Performative utterances. In J.O. Urmson \& G.J. Warnock (Eds.), Philosophical Papers (pp. 233-252). London: Oxford University Press.

Baerenholdt, J.O., Haldrup, M., Larsen, J. \& Urry, J. (2004). Performing tourist places. Burlington: Ashgate.

Bax, M. (1991). Marian apparitions in Medjugorje: Rivalling religious regimes and state formation in Yugoslavia. In E.N. Wolf (Ed.), Religious regimes and state formation: 
Perspectives from European ethnology (pp. 29-54). Albany, NY: University of New York Press.

Belhassen, Y. \& Caton, K. (2006). Authenticity matters. Annals of Tourism Research, 33(3), 853-856.

Belhassen, Y., Caton, K. \& Stewart, T. (2008). The search for authenticity in the pilgrim experience. Annals of Tourism Research, 35(3), 668-689.

Bell, E. (2008). Theories of performance. Los Angeles: Sage.

Bendix, R. (1989). Tourism and cultural displays: Inventing traditions for whom? The Journal of American Folklore, 102(404), 131-146.

Blundell, V. (1993). Aboriginal empowerment and souvenir trade in Canada. Annals of Tourism Research, 20(1), 64.83.

Bruner, E. (2005). Abraham Lincoln as authentic reproduction. In E. Bruner (Ed.), Culture on tour (pp. 145-168). Chicago: University of Chicago Press.

Buchmann, A., Moore, K. \& Fisher, D. (2010). Experiencing film tourism: Authenticity \& fellowship. Annals of Tourism Research, 37(1), 229-248.

Butler, J. (1990). Performative acts and gender constitution: An essay in phenomenology and feminist theory. In S. Case (Ed.), Performing feminisms: Feminist critical theory and theatre (pp. 270-282). Baltimore, MD: Johns Hopkins University Press.

Cary, S.H. (2004). The tourist moment. Annals of Tourism Research, 31(1), 61-77.

Catholic News Agency (2010, March 17). Holy See confirms creation of Medjugorje Commission. Retrieved 22 May 2011, from <http://www.catholicnewsagency.com/news/holy_see_confirms_formation_of_medjugorj e_commission/>.

Chamberlain, J.F. (Ed.). (1991). The Ramkahmhaeng controvesy. Bangkok: The Siam Society.

Cohen, E. (1988). Authenticity and commoditization in tourism. Annals of Tourism Research, $15(3), 371-386$ 
Cohen, E. (2007a). "Authenticity" in Tourism Studies: Aprés la lutte. Tourism Recreation Research, 32(2), 75-82.

Cohen, E. (2007b). The "postmodernization" of a mythical event: Naga fireballs on the Mekong. In E. Cohen (Ed.), Explorations in Thai tourism (85-104). Bingley, U.K.: Emerald.

Cohen E. (2010). Medical travel - A critical assessment. Tourism Recreation Research, 35(3), 225-237.

Coleman, S. \& Eade, J. (2004). Introduction: Reframing pilgrimage. In S. Coleman. \& J. Eade (Eds.), Reframing pilgrimage: Cultures in motion (pp. 1-25). London: Routledge.

Cook, P.S. (2010). Constructions and experiences of authenticity in medical tourism: The performances of places, spaces, practices, objects and bodies. Tourist Studies, 10(2), 135153.

Costa, K.A. (2009). Coach fellas: Heritage and tourism in Ireland. Walnut Creek, CA: Left Coast Press.

Crang, M. (1996). Magic kingdom or a Quixotic quest for authenticity? Annals of Tourism Research, 23(2), 415-431.

Edensor, T. (2001). Performing tourism, staging tourism: (Re)producing tourist space and practice. Tourist Studies, 1(1), 59-81.

Edensor, T. (2007). Mundane mobilities, performances and spaces of tourism. Social \& Cultural Geography, 8(2), 199-215.

Evans-Pritchard, D. (1987). The portal case: Authenticity, tourism, traditions, and the law. The Journal of American Folklore, 100(397), 287-296.

Font, X. (2002). Environmental certification in tourism and hospitality: Progress, process and prospects. Tourism Management, 23(3), 197-205.

Gale, T. (2009). Urban beaches, virtual worlds and 'the end of tourism'. Mobilities, 4(1), 119138.

Geertz, C. (1973). Religion as a cultural system. In C. Geertz (Ed.), The interpretation of culture. New York: Basic Books. 
Glover, I.C. (2006). Some national, regional and political uses of archaeology in East and Southeast Asia. In M. Stark (Ed.), Archaeology of Asia (pp. 17-36). Oxford: Blackwell.

Golden, D. (1996). The museum of the Jewish diaspora tells a story. In T. Selwyn (Ed.) The tourist image: Myth and mythmaking in tourism (pp. 223-250). Chichester: Wiley.

Hermkens, A.-K., Jansen, J. \& Notermans, C. (Eds.). (2009). Moved by Mary: The power of pilgrimage in the modern world. Farnham, Surrey: Ashgate.

Hitchcock, M., King, V.T. \& Parnwell, M. (Eds.). (2010). Heritage tourism in Southeast Asia. Copenhagen: NIAS Press.

Hongthong, P. (2003, September 8). Thread: Centuries old stone set in controversy. The Nation [Bangkok].

Jackson, P. (1999). Commodity cultures: The traffic in things. Transactions of the Institute of British Geographers, 24(1), 95-108.

Jory, P. (2003, March 3). Problems of contemporary Thai historiography. Kyoto Review of Southeast Asia. Retrieved 7 May 2011, from <http://kyoto review.csaes.kyotou.ac.jp/issue/issue2/article_251_p.html>.

Keyes, C. (2002). National heroine or local spirit? The struggle over memory in the case of Thao Suranari of Nakhon Ratchasima. In S. Tanabe \& C. Keyes (Eds.), Cultural crisis and social memory: Modernity and identity in Thailand and Laos (pp. 113-136). London: RoutledgeCurzon.

Kim, H., \& Jamal, T. (2007). Touristic quest for existential authenticity. Annals of Tourism Research, 34(1), 181-201.

Knudsen, B.T. \& Waade, A.M. (2010). Performative authenticity in tourism and spatial experience: Rethinking the relation between travel, place and emotion. In B.T. Knudsen and A.M. Waade eds. Re-investing authenticity: Tourism, place and emotions. Bristol: Channel View Publications, pp. 1-19.

Kolås, å. (2004). Tourism and the making of place in Shangri-La. Tourism Geographies, 6(3), 262-278.

Koontz, A. (2010). Constructing authenticity: A review of trends and influences in the process of authentication in consumption. Sociology Compass, 4(11), 977-988. 
Korat Post (circa January 2007). Lady Mo, Suranari Korat Post.mht, last retrieved 25 January 2012.

Kozinets, R.V. (2002). Consumers escape the market? Emancipatory illuminations from Burning Man. Journal of Consumer Research, 29(1), 20-38.

Lacy, J.A. \& Douglass, W.A. (2002). Beyond authenticity: The meanings and uses of cultural tourism. Tourist Studies, 2(1), 5-21.

Lau, R.W.K. (2010). Revisiting authenticity: A social realist approach. Annals of Tourism Research, 37(2), 478-498.

Llamas, R. \& Belk, R. (2011). Shangri-La: Messing with a myth. Journal of Macromarketing, $31(3), 257-275$.

Lorenzini, E., Calzati, V. \& Giudici, P. (2011). Territorial brands for tourism development. Annals of Tourism Research, 38(2), 540-560.

MacCannell, D. (1973). Staged authenticity: Arrangements of social space in tourist settings. American Journal of Sociology, 79(3), 589-603.

MacCannell, D. (1976). The tourist: A new theory of the leisure class. New York: Schocken Books.

Moore, A. (1980). Walt Disney World: Bounded ritual space and the playful pilgrimage center. Anthropological Quarterly, 53(4), 207-218.

Morrison, A.M., Hsieh, S. \& Wang, C. (1992). Certification in the travel and tourism industry: The North American experience. The Journal of Tourism Studies, 3(2), 32-40.

Noy, C. (2009). The politics of authenticity in a national heritage site in Israel. Qualitative Sociology Review, 5(1), 112-129.

Oakes, T. (2006). Get real! On being yourself and being a tourist. In C. Minca \& T. Oakes (Eds.), Travels in paradox: Remapping tourism (pp. 229-250). Lanham: Rowman \& Littlefield.

Obrador, P., \& Carter, S. (2010). Art, politics, memory: Tactical Tourism and the route of anarchism in Barcelona. Cultural Geographies, 17(4), 525-531.

Olsen, K. (2002). Authenticity as a concept in tourism research. Tourist Studies, 2(2), 159182. 
Pretes, M. (1995). Postmodern tourism: The Santa Claus industry. Annals of Tourism Research, 22(1), 1-15.

Reynolds, F.E. (1977). Civic religion and national community in Thailand. Journal of Asian Studies, 36(2), 267-282.

Reisinger, Y. \& Steiner, C.S. (2006). Reconceptualizing object authenticity. Annals of Tourism Research, 33(1), 65-86.

Rickly-Boyd, J.M. (2012). Authenticity and aura: A Benjaminian approach to tourism. Annals of Tourism Research, 39(1), 269-289.

Ryan, C. (1997). Maori and tourism: A relationship of history, constitutions and rites. Journal of Sustainable Tourism, 5(4), 257-278.

Selwyn, T. (1996a). Introduction. In T. Selwyn (Ed.), The tourist image: Myth and mythmaking in tourism (pp. 1-32). Chichester: Wiley.

Sherry, J.F. \& Kozinets, R.V. (2007). Comedy of the commons: Nomadic spirituality at the Burning Man. In R. Belk \& J.F. Sherry (Eds.), Consumer Culture Theory, Vol 11 of Research in Consumer Behavior (pp. 119-147). Oxford: Elsevier.

Skrbiš, Z. (2005). The apparitions of the Virgin Mary of Medjugorje: The convergence of Croatian nationalism and her apparitions. Nations and Nationalism, 11(3), 443-461.

Smith, J.Z. (1987). To take place: Toward theory in ritual. Chicago: The University of Chicago Press.

Steiner, C.J. \& Reisinger, Y. (2006a). Understanding existential authenticity. Annals of Tourism Research, 33(2), 299-318.

Steiner, C.J. \& Reisinger, Y. (2006b). Reply to Belhassen and Caton. Annals of Tourism Research, 33(3), 856-858.

Suntikul, W., Butler, R. \& Airey, D. (2010). Vietnam's heritage attractions in transition. In M. Hitchcock, V.T. King \& M. Parnwell (Eds.), Heritage tourism in Southeast Asia (pp. 202-220). Copenhagen: NIAS Press.

The Telegraph (2009, 17 July). Blarney Stone named world's most unhygienic attraction. Retrieved 31 January 2012, from 
<http://www.telegraph.co.uk/news/newstopics/howaboutthat/5553820/Blarney-Stonenamed-worlds-most-unhygienic-attraction.html>.

Turner, V. (1973). The center out there: Pilgrim's goal. History of Religions, 12, 191-230.

Wang, N. (1999). Rethinking authenticity in tourism experience. Annals of Tourism Research, 26(2), 349-370.

Wang, N. (2000). Tourism and modernity: A sociological analysis. Oxford: Pergamon Press.

Xie, P.F. (2011). Authenticating ethnic tourism. Bristol: Channel View Publications. 